Original Research Paper

\title{
Geometrical and Physical Effects on the Instability of a Fluid- Conveying Pipe
}

\author{
${ }^{1}$ Dahmane Mouloud, ${ }^{2}$ Samir Zahaf, ${ }^{3}$ Benkhettab Mohamed, ${ }^{1}$ Djilali Boutchicha and ${ }^{4}$ Mawhoub Soubih \\ ${ }^{1}$ LMA, Department of Mechanical Engineering, USTO-MB, BP 1055 El Menaour, Oran 31000, Algeria \\ ${ }^{2}$ Department of Technology, University of Djilali Bounaama-Khamis Meliana, Ain Defla-Algeria \\ ${ }^{3}$ Department of Mechanical Engineering, Mostaganem University-Abdelhamid Ibn Badis, Algeria \\ ${ }^{4}$ Labortory of Mechanics and Energy, Chlef University Hassiba Benbouali, Chlef, Algeria
}

\author{
Article history \\ Received: 08-08-2020 \\ Revised: 20-10-2020 \\ Accepted: 02-11-2020 \\ Corresponding Author: \\ Samir Zahaf \\ Department of Technology, \\ University of Djilali \\ Bounaama-Khamis Meliana, \\ Ain Defla-Algeria \\ Email: samir.zahaf@univ-dbkm.dz \\ zahafsamir1983@gmail.com
}

\begin{abstract}
The endeavor of this paper is to calculate frequencies and critical velocity of pipe carrying incompressible fluid are obtained using standard finite element method. Finite element beam type with two degrees of freedom per node was used. The natural frequencies of our system are calculated by using a program developed on MATLAB. The results are compared with those predicted by the differential transformation method and with other results listed in the literature, where several examples were studied, for pipes with different boundary conditions: Pinned-pinned and clamped-pinned. We determine the influence of the effect of mass ratio, length and elastic foundation of the proper frequencies and the critical velocity for fluid conveying pipe to study and analyze instability with its concepts.
\end{abstract}

Keywords: Pipe Carrying Fluid, Frequencies, Velocity, Winkler Elastic Foundation, FEM, MATLAB, Instability

\section{Introduction}

Pressure pulsations and mechanical vibrations in pipe systems may cause excessive noise and may even lead to damage of piping or machinery. The excitation mechanism can be hydraulic or mechanical (Antaki, 2003). In fluid-filled pipe systems pulsations and vibrations will be strongly coupled. The elastic fluid coupling forces depend on the relative movement of the structure, it gives coupling effects from mass, stiffness, damping, the coupling can cause dynamic instability by negative damping and one then has a fluid-elastic instability. We will be particularly interested in the case of a pipe with an internal flow, (Païdoussis, 1970; 1981; Païdoussis and Besancon, 1981; Païdoussis and Curling, 1985; Païdoussis and Moon, 1988; Païdoussis et al., 2007).

The first works on the subject are however those of (Bourrières, 1939), who obtained the linear equations of motion and made experimental observation of the oscillations of a cantilevered pipe. The effect of internal fluid on free vibration of a pipe was studied by (Païdoussis and Li, 1993).

Dahmane et al. (2016) have studied the effect of Coriolis force of the internal fluid of pipeline by analytical approach using Galerkin method. Results show that Coriolis force reduces frequencies, especially at higher speeds. There are others who used analytical method to study dynamic of pipe with internal fluid under different parameters as, differential quadrature method (Lin and Qiao, 2008), differential transformation method (Ni et al., 2011) and such a generalized integral transform technique (Gu et al., 2013). The results showed that flow velocity reduces the first natural frequencies, which affects the stability of the system. Independently analytical methods, numerical methods are very effective and faster to treat a physical problem of vibration under internal flow, such as finite element method (Lee and Park, 2006; Sadeghi and Karimi-Dona, 2011; Mostafa, 2014; Jiya et al., 2018; Mouloud et al., 2020). The numerical results showed that the geometrical parameters have a great influence on the stability of the pipeline systems.

All these studies did not address the issue of the system stability, except what we find in (Doaré and de Langre, 2002a; 2002b; 2000; 2006); they have calculated critical velocity of liquid under the effect of physical and geometrical parameters of the system and then study the two aspects of instability. Nevertheless, all these works do not take into account the fluid whether Newtonian or not, the effect of the parameter different on dynamic instability with different boundary conditions, study the margin (range) of static and dynamic instability by the numerical approach. 
In the present study calculation methods have been developed for the analysis of vibrations in fluid-filled pipe systems. The analytical model is based on the Newtonian approach. The practicability of the calculation model and the effects of fluid-structure interaction are illustrated by calculations for some simple systems, for pipes with different boundary conditions pinned-pinned and clamped-pinned.

The numerical methods were developed, modeling of solid-fluid was conducted by the standard finite element method; finite element beam type with two degrees of freedom per node was used. The frequencies of the system are calculated using a program developed on MATLAB language. After studying the convergence and validated program with (Ni et al., 2011), several examples were studied. The study of these examples enabled us to determine the influence of these physical and geometrical parameters of the natural frequencies and consequently their stability.

\section{Derivation of Governing Differential Equation}

The problem to be considered is the vibration analysis of a fluid conveying pipe system on an elastic foundation. The derivation of the equation is based on Euler-Bernoulli elementary beam theory. The physical model of conveying pipe carrying fluid is shown in Fig. $1 \mathrm{a}$ and $1 \mathrm{~b}$ shows forces on fluid element while, Fig. 1c shows forces and moment of pipe element.

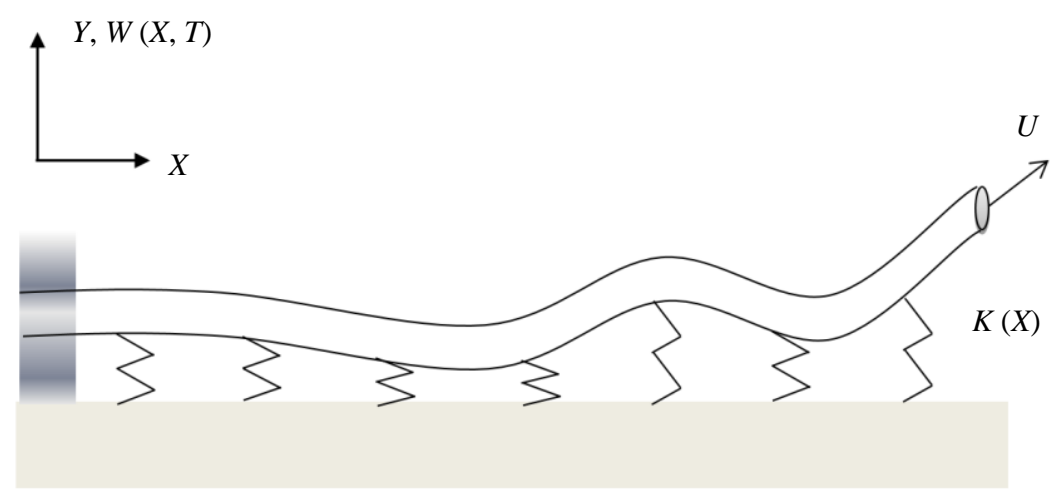

(a)

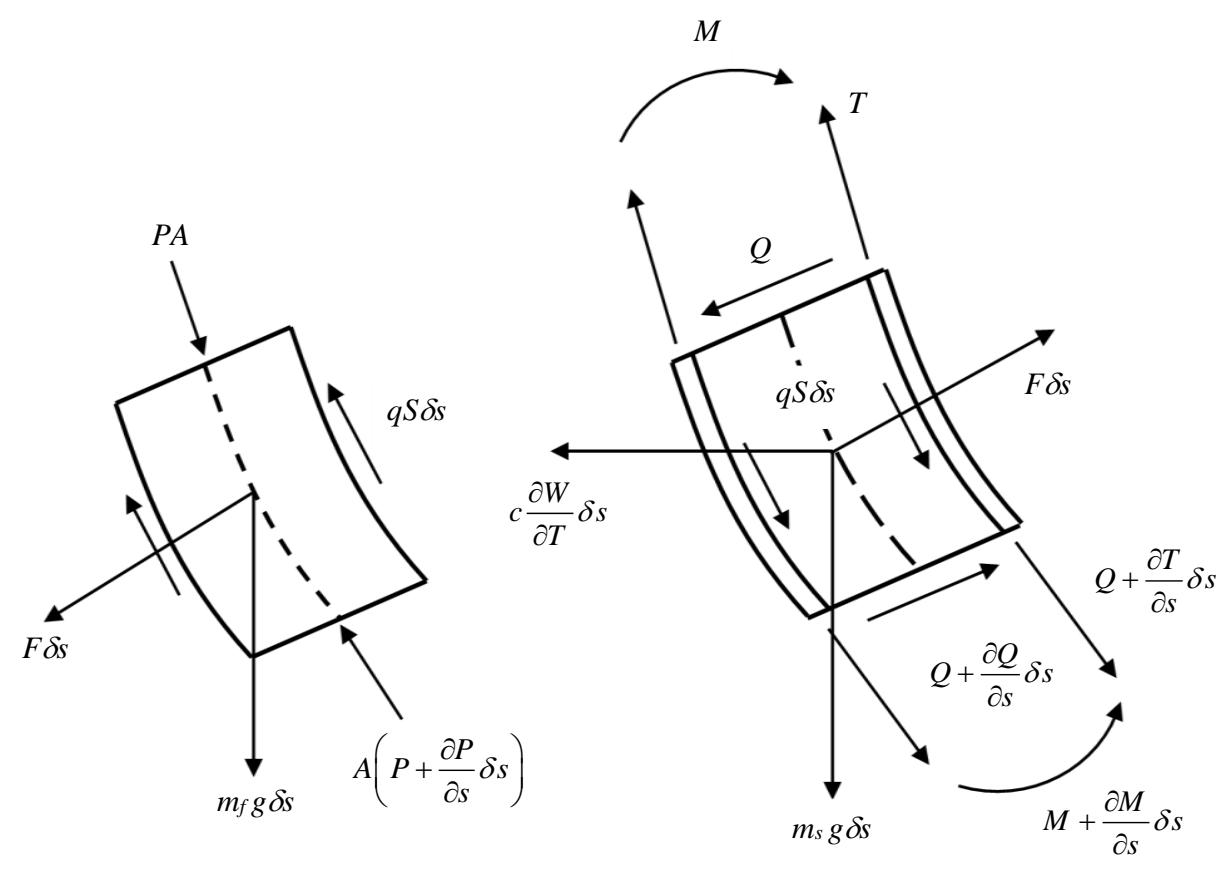

(b)

(c)

Fig. 1:(a) Representation of the pipe-conveying fluid resting on an elastic Winkler-type, (b) forces on fluid element; (c) forces and moments on pipe element $\delta$ s (Païdoussis, 1998) 


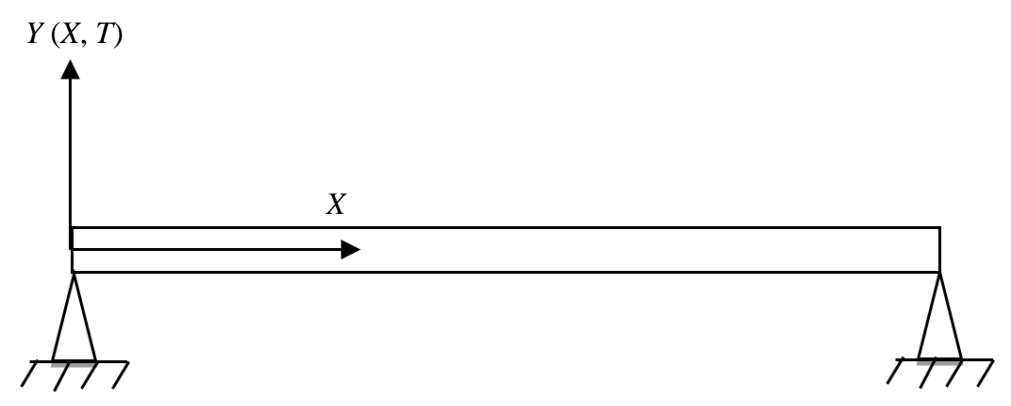

Fig. 2: Pinned-pinned pipe

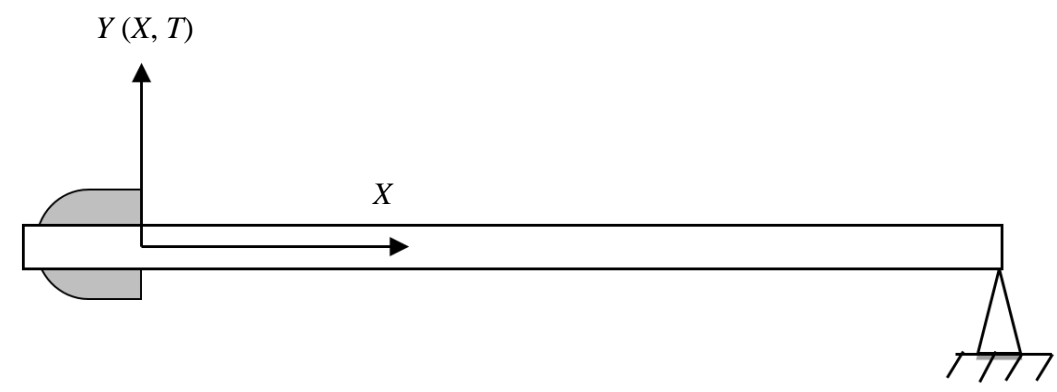

Fig. 3: Clamped-pinned pipe

The pipe is long and straight $L$ conveying an incompressible fluid with steady speed $U$; the motions are small $\delta s$.

The pipe rests on an elastic foundation Winklermodel soil of modulus $K X, m_{s}$ and $m_{f}$ the masses per unit length of the pipe and the fluid, respectively. The Boundary conditions are:

a. Pinned-Pinned Pipe (Fig. 2):

$$
\left.Y\right|_{X=0}=\left.\frac{\partial^{2} Y}{\partial X^{2}}\right|_{X=0}=\left.Y\right|_{X=L}=\left.\frac{\partial^{2} Y}{\partial X^{2}}\right|_{X=L}=0
$$

b. Clamped-Pinned Pipe (Fig. 3):

$$
\left.Y\right|_{X=0}=\left.\frac{\partial Y}{\partial X}\right|_{X=0}=\left.Y\right|_{X=1}=\left.\frac{\partial^{2} Y}{\partial X^{2}}\right|_{X=1}=0
$$

The equation for conveying pipe carrying fluid on a Winkler elastic foundation is given as (Doaré and de Langre, 2000):

$E I \frac{\partial^{4} Y}{\partial X^{4}}+m_{f} U^{2} \frac{\partial^{2} Y}{\partial X^{2}}+2 m_{f} U \frac{\partial^{2} Y}{\partial X \partial T}+\left(m_{s}+m_{f}\right) \frac{\partial^{2} Y}{\partial T^{2}}+K Y=0$

\section{Finite Element Discretization}

The Equation (3) is a fourth-order partial differential equation in two independent variables subject to various boundary conditions. It is not easy to get its analytical solution, but through the use of finite element method we get its numerical solution (Fig. 4). The equation of element deflection for straight two dimensional beam element could have the form (Rao, 2004):

$W(X, T)=\sum_{i=1}^{N} N_{i}(X) W_{i}(T)$

Where:

$\left[N_{i}\right]=$ Represent the shape function,

$W_{i}(T)=$ The function which represents the shape of the displacements and rotations at nodes (the generalized coordinates)

Therefore, Equation (4) becomes:

$W(X, T)=N_{1}(X) W_{1}(T)+N_{2}(X) \theta_{1}(T)$

$+N_{3}(X) W_{2}(T)+N_{4}(X) \theta_{2}(T)$

and:

$$
\begin{aligned}
& \theta(X, T)=N_{1}^{\prime}(X) W_{1}(T)+N_{2}^{\prime}(X) \theta_{1}(T) \\
& +N_{3}^{\prime}(X) W_{2}(T)+N_{4}^{\prime}(X) \theta_{2}(T)
\end{aligned}
$$

\section{Determination of the Element Matrices}

By using the energy principle. The potential (deformation) energy and the kinetic energy of the solid element can be expressed by (Rao, 2011; Shizhong et al., 1998; Zhai et al., 2011): 
$V_{s}=\frac{1}{2} \int_{0}^{L} E I\left(\frac{d^{2} W}{d X^{2}}\right)^{2} d X$

$T_{s}=\frac{1}{2} \int_{0}^{L} m_{s} \frac{d^{2} W}{d T^{2}} d X$

The kinetic energy of the fluid element can be expressed by (Sadeghi and Karimi-Dona, 2011):

$T_{f}=\frac{1}{2} \int m_{f}\left(U \frac{d W}{d X}+\frac{d W}{d T}\right)^{2} d X$

The potential energy over the length of elastic foundation can be expressed by (Mostafa, 2014):

$V^{\prime}=\frac{1}{2} \int_{0}^{L} K W^{2} d X$

The different elementary matrices can be represented as follows:

$$
\begin{aligned}
& {\left[K_{s}\right]=\frac{m_{f} U^{2}}{30 L}\left[\begin{array}{cccc}
12 & 6 L & -12 & 6 L \\
6 L & 4 L^{2} & -6 L & 2 L^{2} \\
-12 & -6 L & 12 & -6 L \\
6 L & 2 L^{2} & -6 L & 4 L^{2}
\end{array}\right]} \\
& {\left[K_{f}\right]=\frac{m_{f} U^{2}}{30 L}\left[\begin{array}{cccc}
36 & 3 L & -36 & 3 L \\
3 L & 4 L^{2} & -3 L & -L^{2} \\
-36 & -3 L & 36 & -3 L \\
3 L & 3 L^{2} & -3 L & 4 L^{2}
\end{array}\right]} \\
& {[M]=\frac{\left(m_{s}+m_{f}\right) L}{420}\left[\begin{array}{cccc}
156 & 22 L & 54 & -13 L \\
22 L & 4 L^{2} & 13 L & -3 L^{2} \\
54 & 13 L & 156 & -22 L \\
-13 L & -3 L^{2} & -22 L & 4 L^{2}
\end{array}\right]} \\
& {[C]=\frac{2 m_{f} U}{30}\left[\begin{array}{cccc}
-30 & 6 L & 30 & -6 L \\
-6 L & 0 & 6 L & -L^{2} \\
-30 & -6 L & 30 & 6 L \\
6 L & L^{2} & -6 L & 0
\end{array}\right]}
\end{aligned}
$$

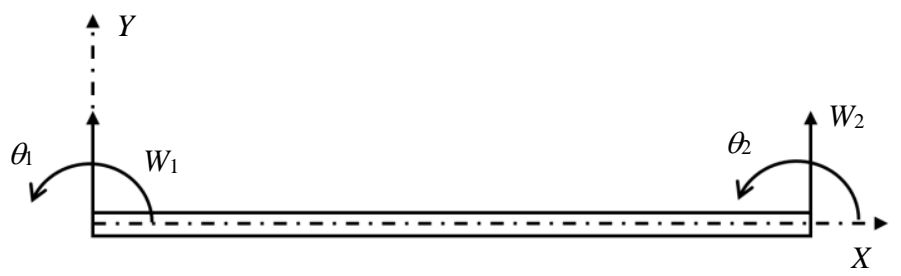

Fig. 4: Beam element nodal displacements 
Therefore, we can obtain the natural frequencies (Eigen-values) and mode shapes (Eigen vectors) by solving the mathematically well-known characteristic equation of:

$$
\lambda I-H z=0
$$

where, $\lambda$ is Eigen-values of the system and $I$ is a unity matrix and:

$$
H=\left[\begin{array}{cc}
0 & I \\
-M^{-1} K & -M^{-1} C
\end{array}\right]
$$

The solution of Equation (22) can be written in the following form:

$$
\begin{aligned}
& \{q\}=\{E\} \cdot \exp (\lambda t) \\
& z=\left\{\begin{array}{c}
\lambda\{E\} \\
\{E\}
\end{array}\right\} \exp (\lambda t)=\{\tilde{E}\} \exp (\lambda t)
\end{aligned}
$$

We obtain a homogeneous equation, which corresponds to a generalized Eigen value problem of our system:

$$
\left\{\left[\begin{array}{cc}
0 & I \\
-M^{-1} K & -M^{-1} C
\end{array}\right]-\lambda\left[\begin{array}{cc}
I & 0 \\
0 & I
\end{array}\right]\right\}\left[\begin{array}{c}
\lambda\{E\} \\
\{E\}
\end{array}\right]=\left[\begin{array}{l}
0 \\
0
\end{array}\right]
$$

We can compute the Eigen-values numerically from Equation (26) and obtain the Eigen-frequencies of conveying pipe carrying fluid for different various parameter values. The Eigen-values are complex:

$$
\lambda^{m}=\operatorname{Re}^{m}+j \omega^{m}
$$

where, $\lambda^{m}$ is the complex eigenvalue, $R e$ is real part of Eigen-frequencies and the imaginary part of these roots represents the natural frequencies of damped system and $m=1,2, \ldots . N ; \mathrm{j}=\sqrt{-1}$, The critical flow velocity $u_{c r}$ is characterized by $\max \left(R e^{m}=0\right)$,

The characteristic roots $\mathrm{m}$ is obtained here by using the (eig) function of MATLAB. Using the nondimensional parameters (Païdoussis, 1998), we obtain:

$$
\beta=\frac{m_{s}}{m_{f}+m_{s}}, k=\frac{K L^{4}}{E I}, \Omega=\left(\frac{m_{f}+m_{s}}{E I}\right)^{1 / 2} \omega L^{2}, u=\left(\frac{m_{f}}{E I}\right)^{1 / 2} U L^{2}
$$

\section{Results and Discussion}

In the current work, we rely on calculating the critical fluid velocity to study and analyze instability with its concepts. Results will be discussed for various values of $\beta$, length $L$, elastic foundation $k$ (Winkler type) for pipes with different boundary conditions. Because the problem is very ramified, we use incompressible fluid and the physical parameters as:

- $\quad$ Elastic modulus of pipe is (211 GPa)

- $\quad$ Pipe length is $(1 \div 2 \mathrm{~m})$

- Fluid density is $\left(1000 \mathrm{~kg} / \mathrm{m}^{3}\right)$

- $\quad$ Pipe density is $\left(7850 \mathrm{~kg} / \mathrm{m}^{3}\right)$

- $\quad$ Pipe thickness for $(\beta=0.1 \div 0.5)$

- Outer diameter of the pipe is $(0.03 \mathrm{~m})$

\section{Pinned-Pinned Pipe with Internal Flow}

The object of this section is the determination of proper frequencies for fluid conveying pipe without foundation. First, the validation of our program was made by doing a convergence study, convergence was performed for a velocity $\mathrm{U}=100 \mathrm{~m} / \mathrm{s}$ Fig. 5a, another study for critical velocity where $U=175 \mathrm{~m} / \mathrm{s}$, the results obtained are shown in Fig. 5b. The Fig. 5a shows that there is very fast convergence for the first two modes according to the number of elements and that for two different fluid velocities. Convergence is obtained for the third mode with 13 elements. On the other hand, the numerical results are given and compared with those obtained by DTM (Ni et al., 2011) for pinned-pinned pipe with internal flow; the results obtained numerically are similar to those obtained by the analytical approach (Fig. 6). Figures 7 and 8 represent the first Eigen-modes of pipe on simple supports for different mass ratios, (a) dimensionless frequencies, (b) natural frequencies $(\mathrm{Hz})$, it appears clearly on these figures that the mass ratio influences the first modes and consequently on the critical velocity and the stability of our system, these figures clearly show the distinction between the Eigen-modes and the combined modes. We notice that the third critical speed is 9.44; this is not what we found in the previous literatures. The Fig. 9 (physic results) and the Fig. 10 (Nondimensional frequency) show the natural frequencies as a function of the fluid velocity for different length with two mass ratio. We observe in the Fig. 9 that the critical speed is $170.27 \mathrm{~m} / \mathrm{s}$ for a length of $1 \mathrm{~m}$ and 110 $\mathrm{m} / \mathrm{s}$ for $2 \mathrm{~m}$, we also note that the previous studies have not addressed the effect of these parameters; obviously the length of the pipe has destabilizing effect on the vibration of the system. The Fig. 10 shows the field of instability, where the flow velocity is critical or rather the pulsation of the system is zero, as we note that this instability margin changes according to length, which affects the stability of both types, we will explain in what follows this development in detail. 


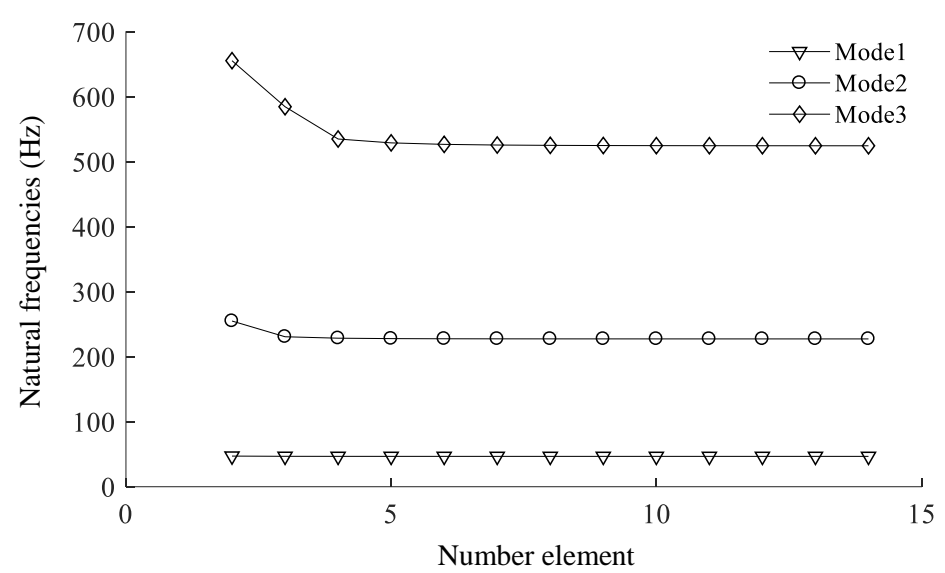

(a)

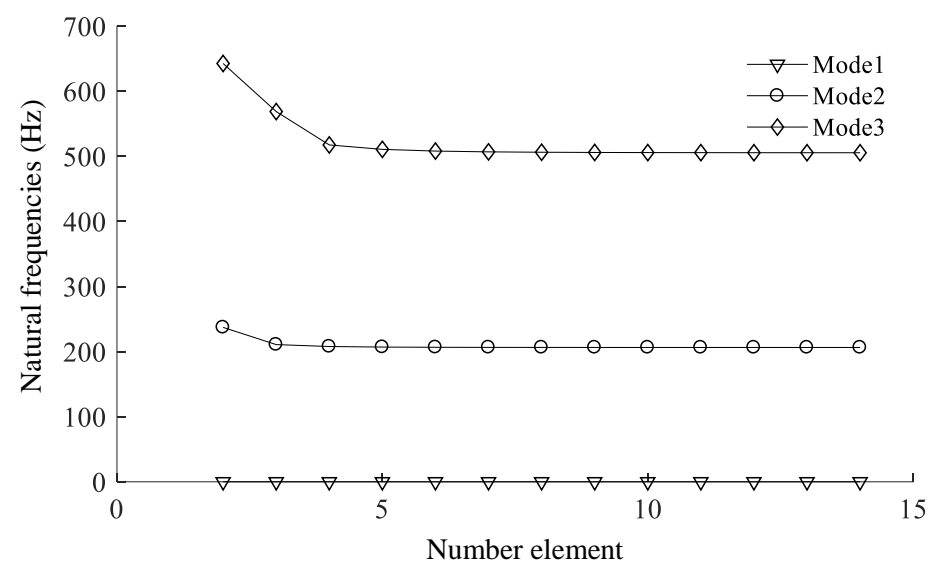

(b)

Fig. 5: Convergence of the first three natural frequencies of pinned-pinned pipe, (a) $U=100 \mathrm{~m} / \mathrm{s}$, (b) $U=175 \mathrm{~m} / \mathrm{s}, \beta=0.5$

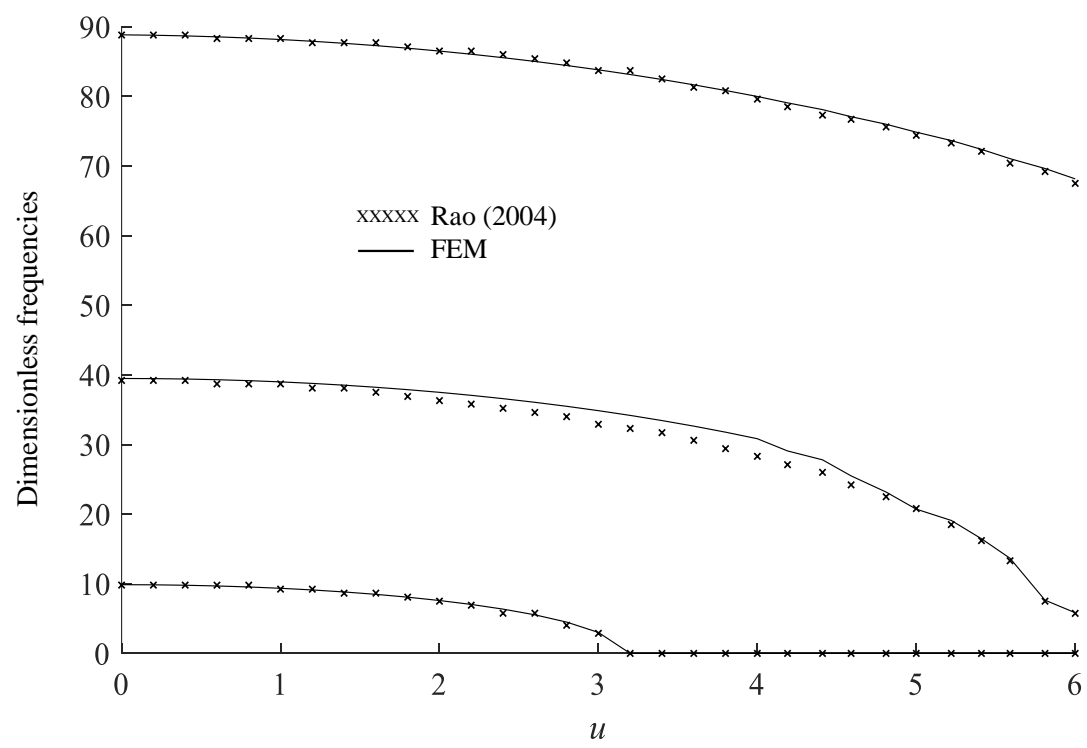

Fig. 6: Dimensionless frequency for various values of $u$, for the lowest three modes of a pinned-pinned pipe conveying fluid, comparison DTM (Ni et al., 2011) (xxx) and FEM ( ), $\beta=0.1$ 


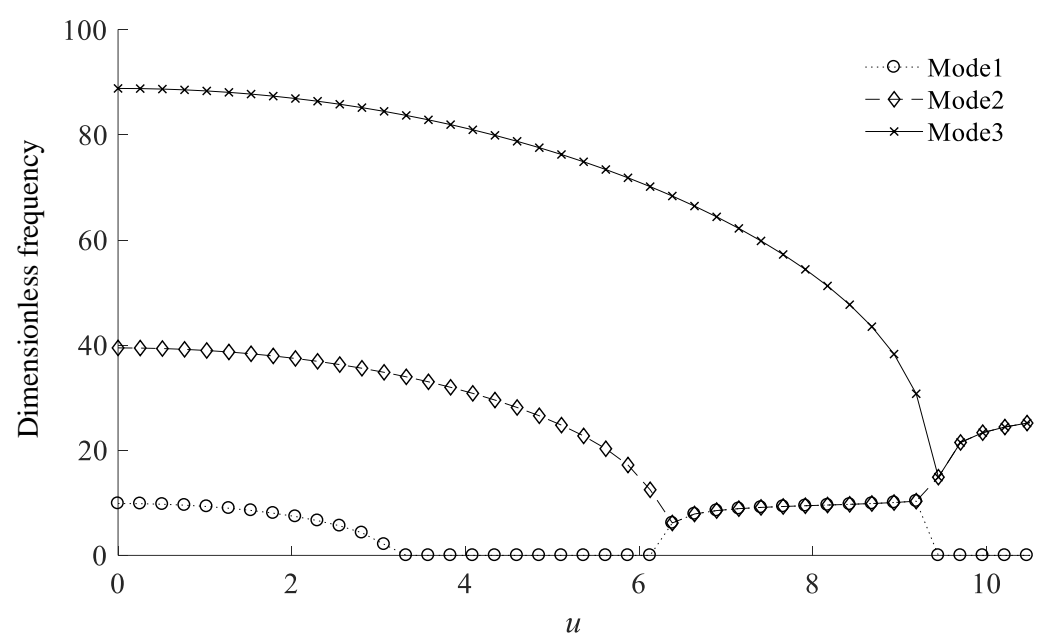

(a)

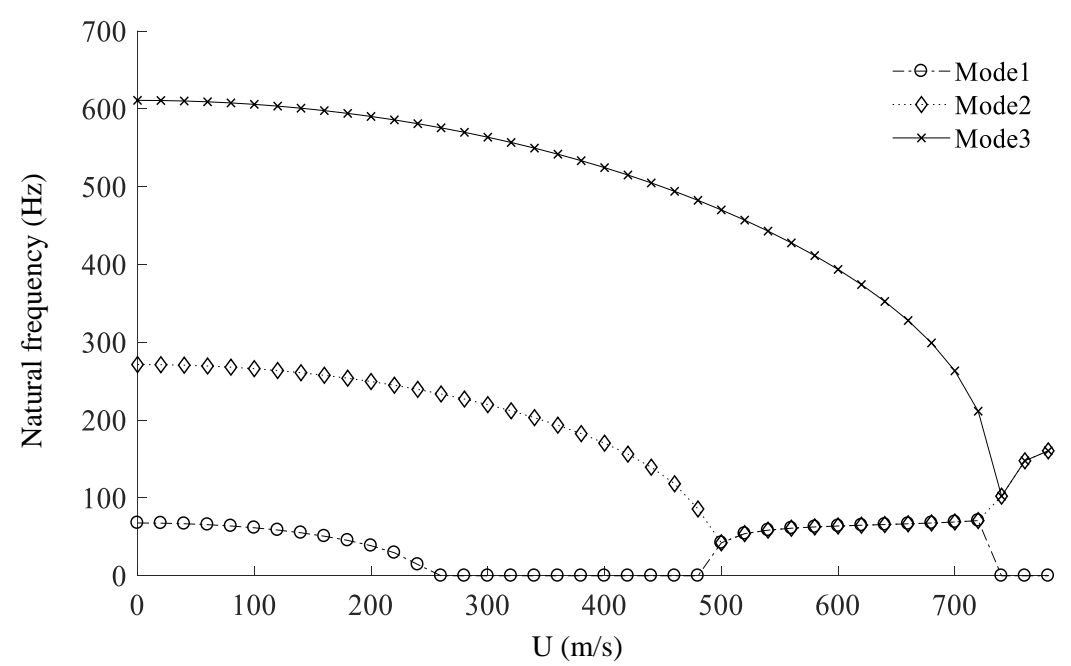

(b)

Fig. 7: Three proper modes on fluid velocity function of pinned-pinned pipe conveying fluid, $\beta=0.3$, (a) dimensionless frequencies, (b) naturel frequencies $(\mathrm{Hz})$

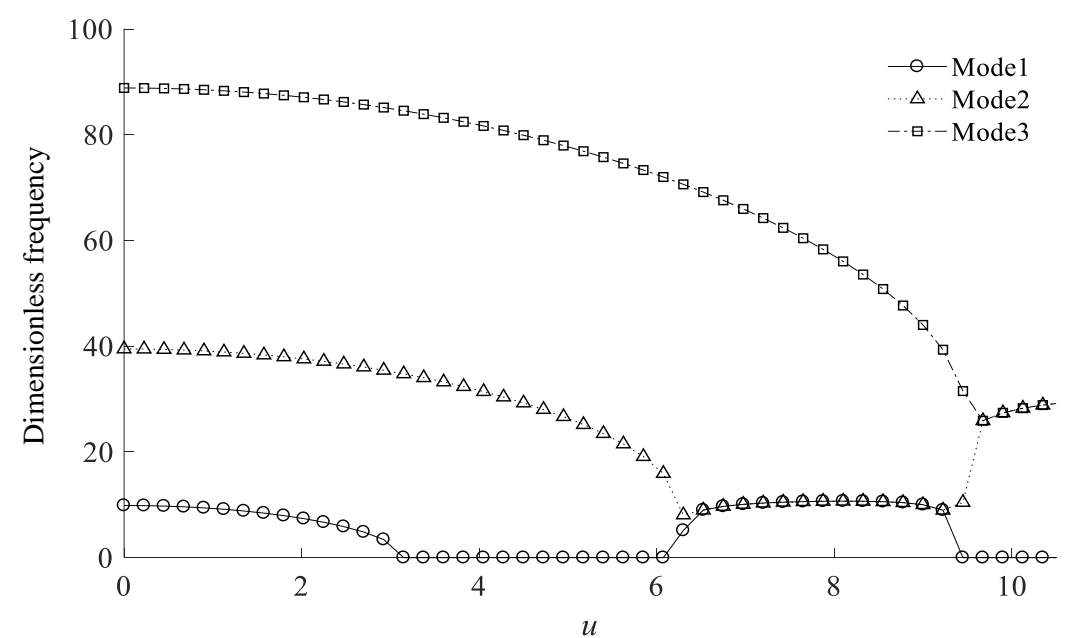

(a) 
Dahmane Mouloud et al. / Current Research in Bioinformatics 2020, Volume 9: 56.69 DOI: 10.3844/ajbsp.2020.56.69

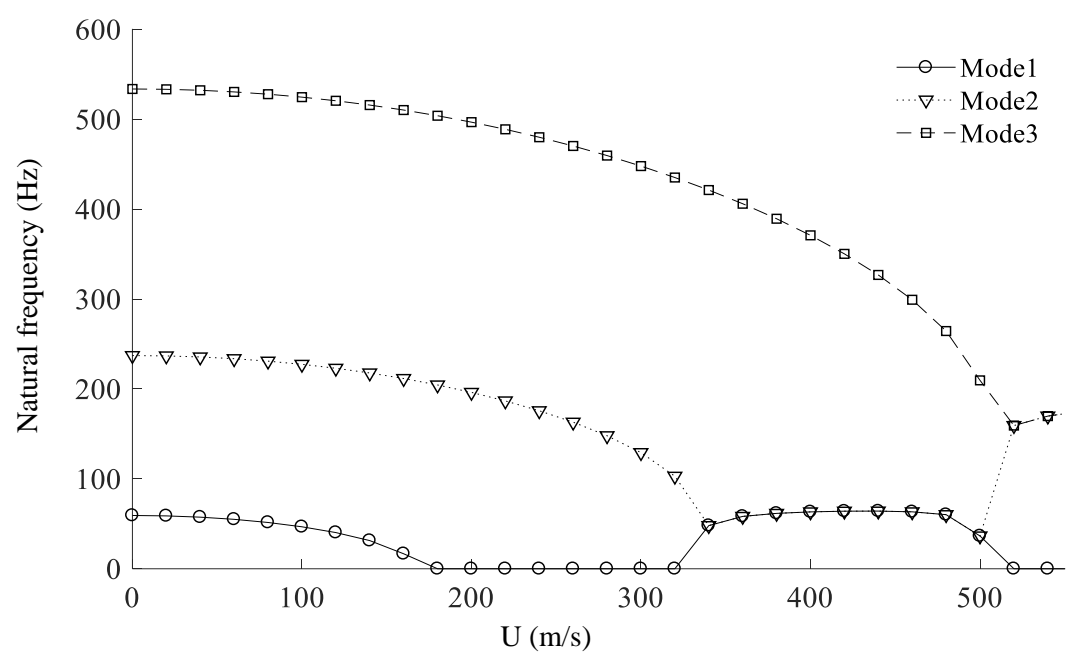

(b)

Fig. 8: Three proper modes on fluid velocity function of pinned-pinned pipe conveying fluid, $\beta=0.5$, (a) dimensionless frequencies, (b) naturel frequencies $(\mathrm{Hz})$
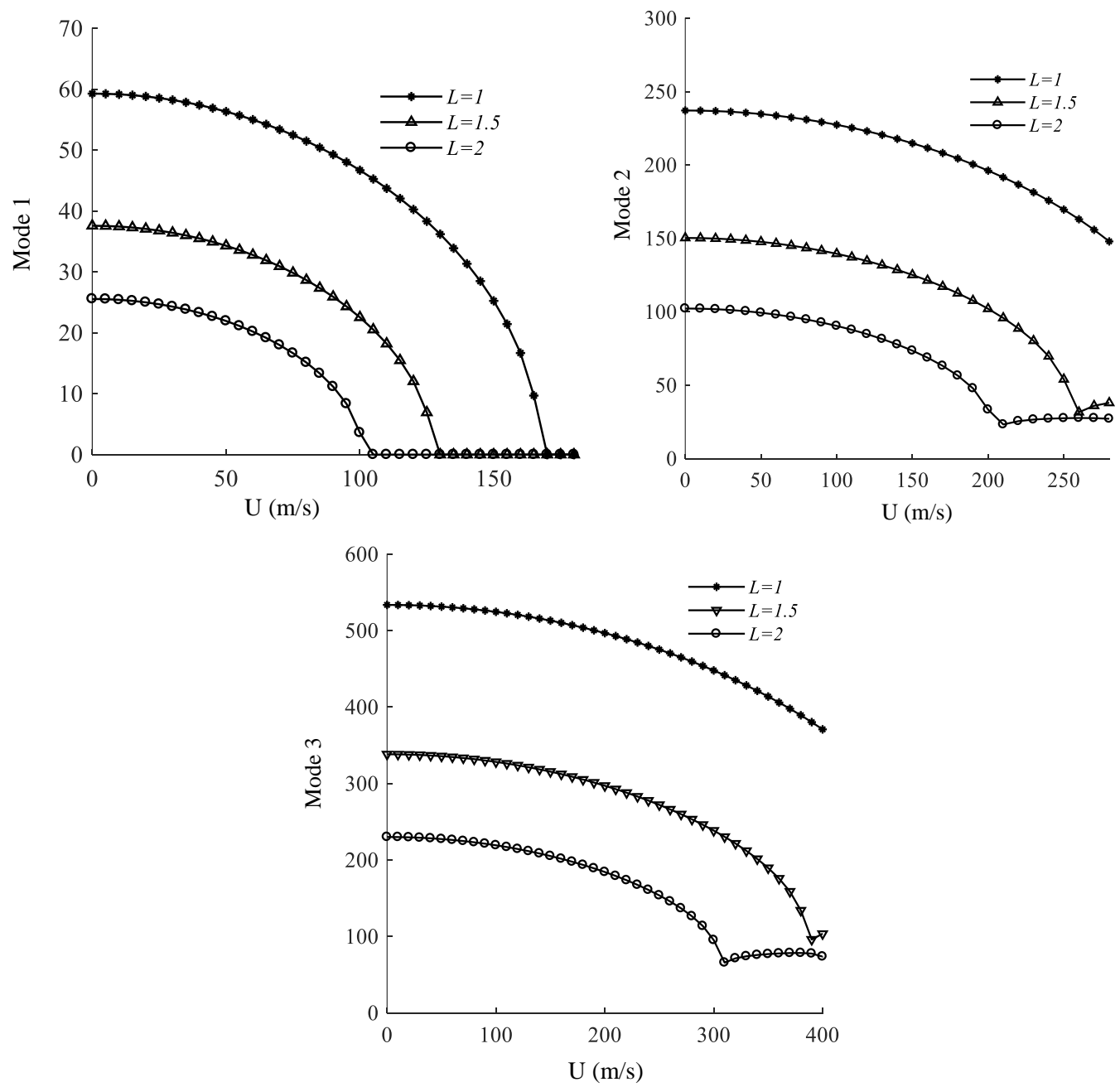

Fig. 9: Effect of length on the natural frequency of the pinned-pinned pipe at different fluid velocities, $\beta=0.5$ 

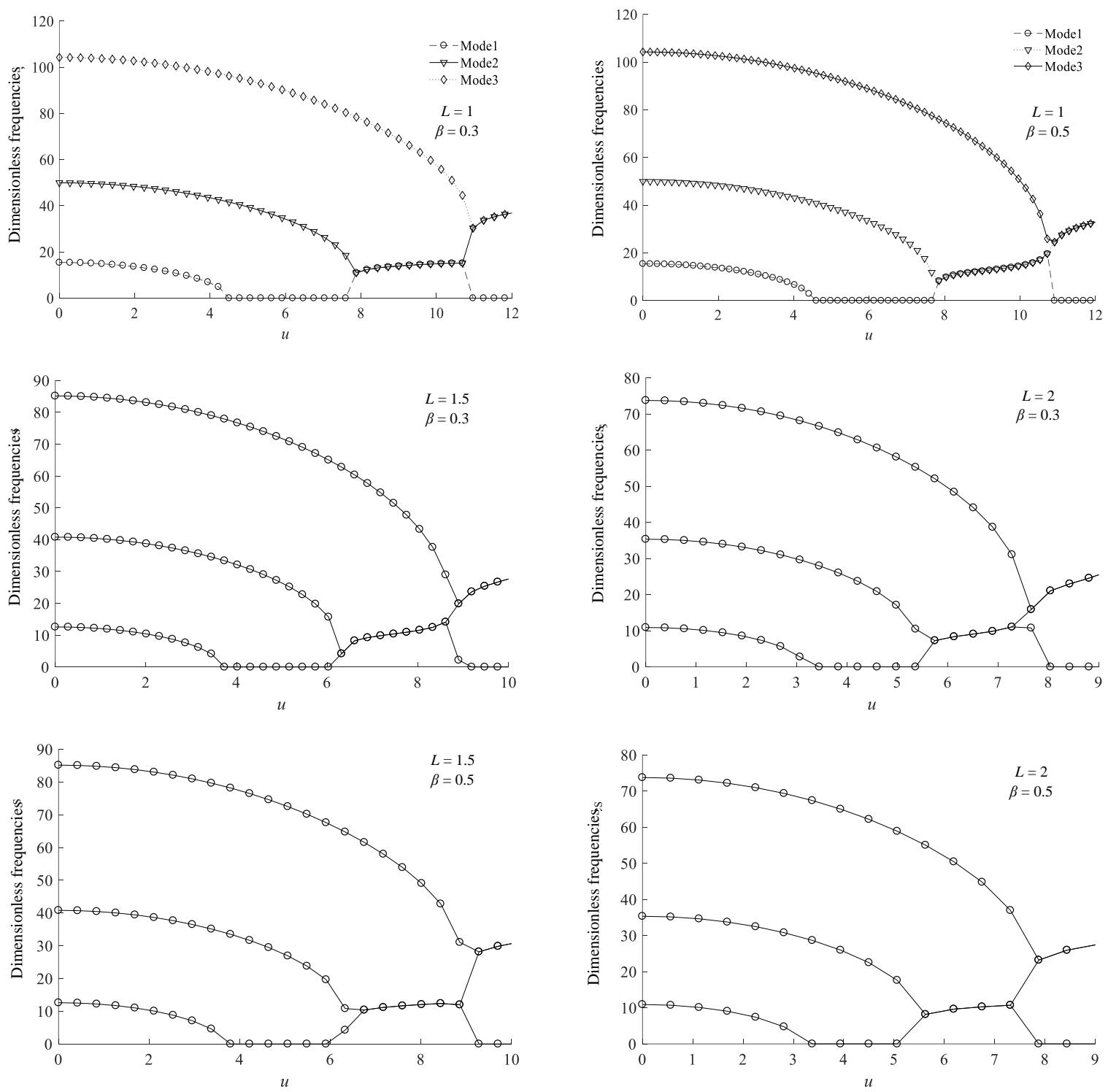

Fig. 10: Effect of length on the natural frequency of the pinned-pinned pipe at different fluid velocities for $\beta=0.3$ and $\beta=0.5$

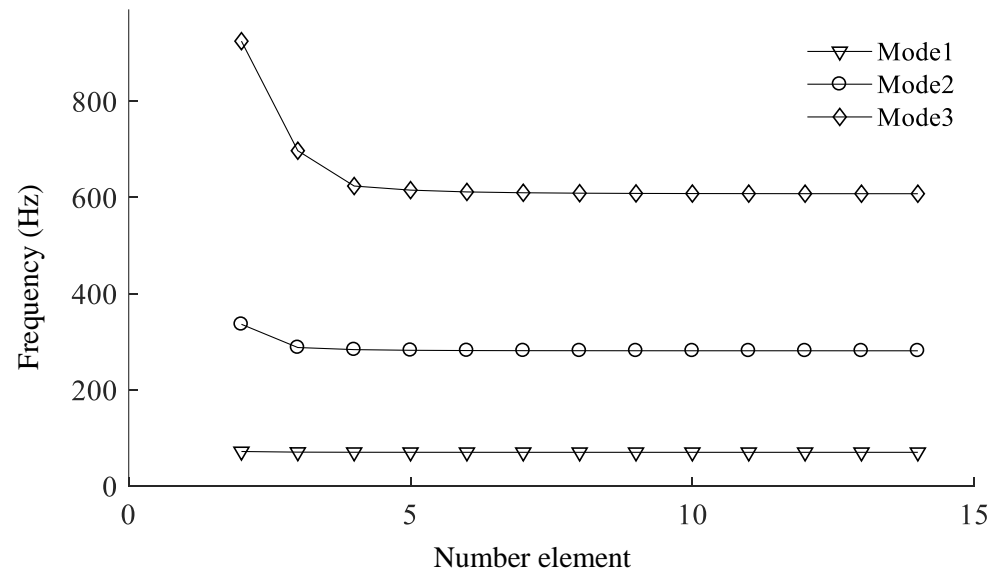

Fig. 11: Convergence of the first three natural frequencies of clamped-pinned pipe, $U=150 \mathrm{~m} / \mathrm{s}, \beta=0.5$ 


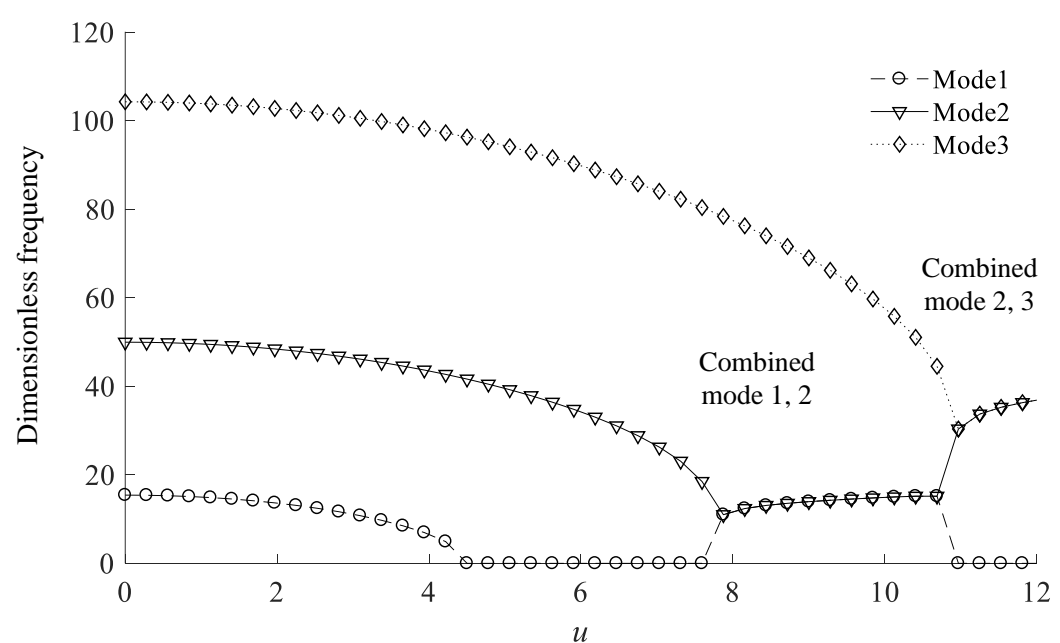

(a)

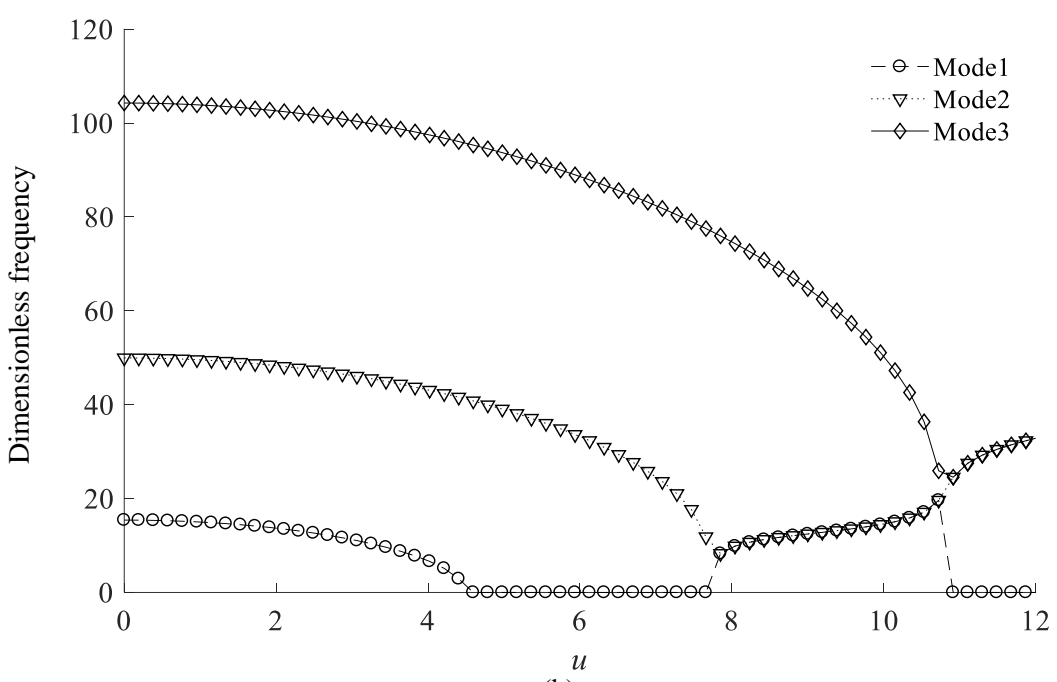

(b)

Fig. 12: Three proper modes on fluid velocity function of clamped-pinned pipe conveying fluid, (a) $\beta=0.3$, (b), $\beta=0.5$

\section{Clamped-Pinned Pipe with Internal Flow}

In this section, the determinations of parameters frequencies for fluid conveying pipe, without and with foundation are calculated using the FEM. Beginning, the convergence was performed for a velocity $U=150$ $\mathrm{m} / \mathrm{s}$, the results obtained are shown in Fig. 11, convergence is obtained for the three modes with 13 elements. Figure 12 present the natural frequency of the pipe at different fluid velocities for $\beta=0.3$ and $\beta$ $=0.5$. Over an interval $\left[\begin{array}{ll}0 & 12\end{array}\right]$, we notice almost same result and same instability range. The Fig. 13 shows the evaluation of these modes as a function of the speed of the fluid for different lengths $L$ for two $\beta$. This figure appears that the increase in $\beta$ implies a reduction in the thickness, that is to say a gain in the mass of the empty pipe, this increase has no great influence on the first mode while its influence the higher modes. For low velocity it is a gain, but at high velocity its effect is destabilizing.

The length has an effect of reducing the rigidity, which lowers the frequencies of the system according to the speed of fluid and consequently quickly reach the first critical velocity of static instability. For $L=1 \mathrm{~m}$, the instability range is equal 3.55 , is reduced to 1.96 for $L=2 \mathrm{~m}$. The effect of the elastic is stabilizing for the system, as show in the Fig. 14 and the length weakens the rigidity of the system and therefore has a destabilizing effect. In addition we note that the instability range of the first mode is reduced as a function of the stiffness. For the parameter $k=1$ and $L$ $=1$, the instability range is equal 3.11 , the range is 1.33 for the parameter $k=1000$, Fig. 14 . 

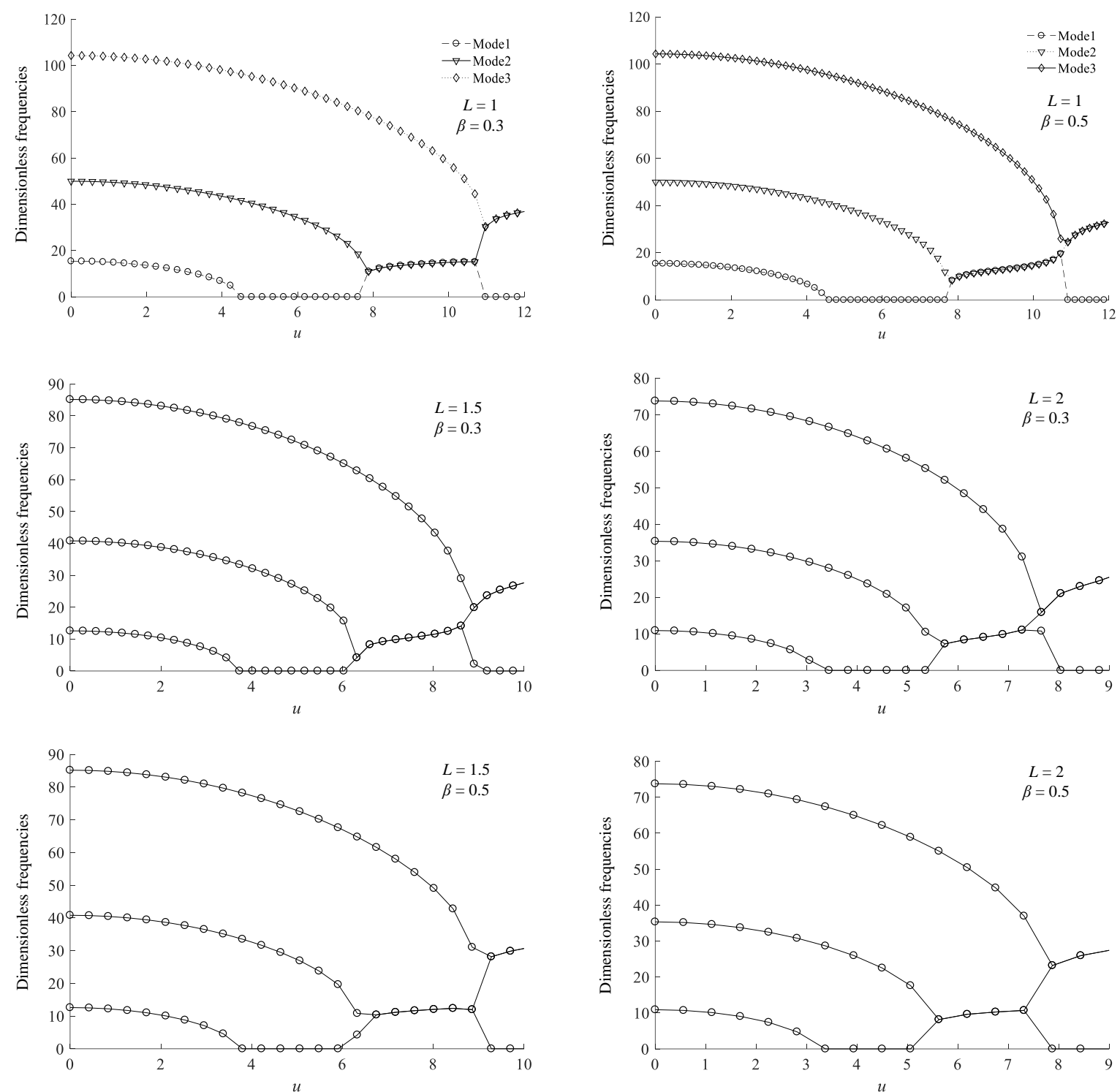

Fig. 13: Effect of length on the natural frequency of the pipe at different fluid velocities
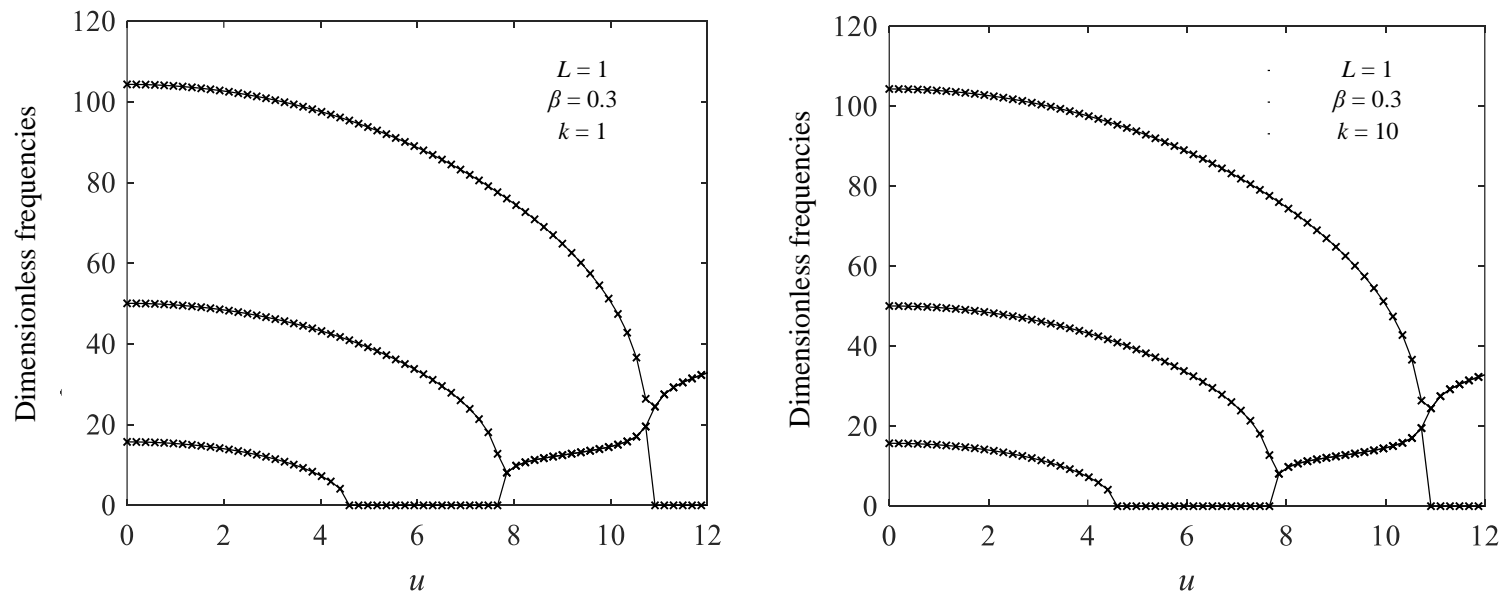

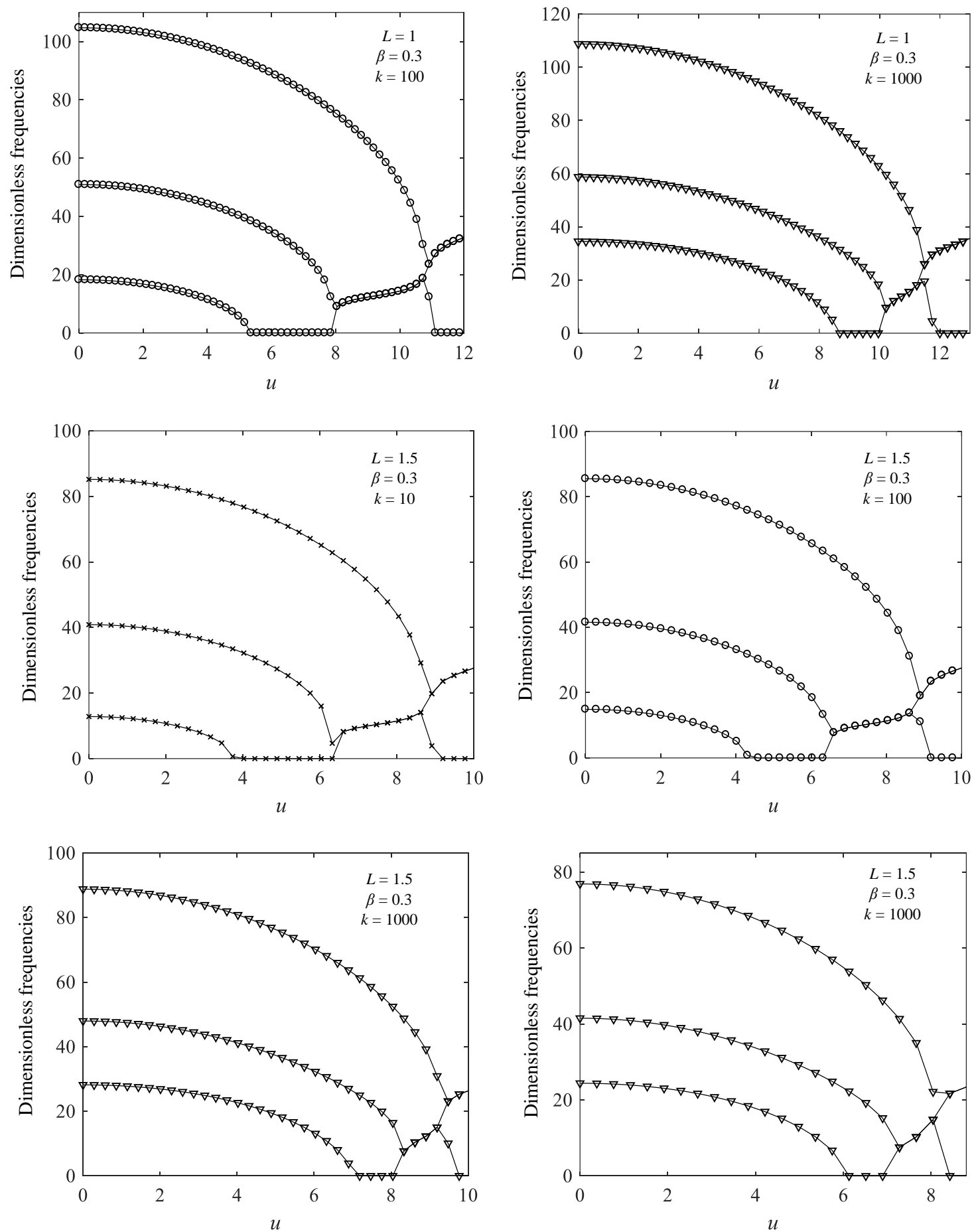

Fig. 14: Effect of foundation stiffness on the natural frequency of the clamped-pinned pipe at different fluid velocities $\beta=0.3$

\section{Conclusion}

We have studied in this study the free vibration of pipe transporting a fluid for different boundary conditions. The numerical aspect with the finite method gives solutions in a complex plane by determining the
Eigen modes, the numerical results are finally combined with the semi-analytic results to determine the different characteristics of instability of each system. The first observation that we can make that the natural frequencies of the system weight the velocity of the fluid. We observe that instability appears when the 
velocity exceed a threshold called critical velocity of instability, when the first frequency is zero. According to the first two cases, we note the distinction between Eigen modes and combined modes (first mode, combination between the first and second, second mode, combination between the second and third, third mode. We have noticed that increasing $\beta$ slightly decreases the rigidity of the system (loss of rigidity) and the system consequently decreases their natural frequencies. The typical elastic foundation of Winkler increases the rigidity of the system and consequently the natural frequencies and the critical velocity. What distinguishes most of this research from others is its discussion of the axis of instability and what it means in this field that is why we did some analysis and calculation in this research, hoping to continue with other work in the same field.

\section{Author's Contributions}

All authors equally contributed in this work.

\section{Ethics}

This article is original and contains unpublished material. The corresponding author confirms that all of the other authors have read and approved the manuscript and no ethical issues involved.

\section{References}

Antaki, G. A. (2003). Piping and pipeline engineering: design, construction, maintenance, integrity and repair. CRC Press.

Bourrières, F. J. (1939). Sur un phénomène d'oscillation auto-entretenue en mécanique des fluides réels: par François-Joseph Bourrières... Préface de M. H [enri] Bénard... E. Blondel La Rougery, Gauthier-Villars.

Dahmane, M., Boutchicha, D., \& Adjlout, L. (2016). One-way fluid structure interaction of pipe under flow with different boundary conditions. Mechanics, 22(6), 495-503.

Doaré, O., \& de Langre, E. (2000, June). Local and global instability of fluid-conveying cantilever pipes.

Doaré, O., \& de Langre, E. (2002a). Local and global instability of fluid-conveying pipes on elastic foundations. Journal of fluids and structures, 16(1), $1-14$.

Doaré, O., \& de Langre, E. (2002b). The flow-induced instability of long hanging pipes. European Journal of Mechanics-A/Solids, 21(5), 857-867.

Doaré, O., \& de Langre, E. (2006). The role of boundary conditions in the instability of one-dimensional systems. European Journal of Mechanics-B/Fluids, 25(6), 948-959.
Gu, J., An, C., Duan, M., Levi, C., \& Su, J. (2013). Integral transform solutions of dynamic response of a clamped-clamped pipe conveying fluid. Nuclear Engineering and Design, 254, 237-245.

Jiya, M., Inuwa, Y. I., \& Shaba, A. I. (2018). Dynamic response analysis of a uniform conveying fluid pipe on two-parameter elastic foundation. Science World Journal, 13(2), 1-5.

Lee, U., \& Park, J. (2006). Spectral element modelling and analysis of a pipeline conveying internal unsteady fluid. Journal of fluids and structures, 22(2), 273-292.

Lin, W., \& Qiao, N. (2008). In-plane vibration analyses of curved pipes conveying fluid using the generalized differential quadrature rule. Computers \& structures, 86(1-2), 133-139.

Mostafa, N. H. (2014). Effect of a Viscoelastic foundation on the Dynamic Stability of a Fluid Conveying Pipe. International Journal of Applied Science and Engineering, 12(1), 59-74.

Mouloud, D., Zahaf, S., Soubih, M., Slimane, S. A., Mohamed, B., \& Boutchicha, D. (2020). Numerical study of post-buckling of clamped-pinned pipe carrying fluid under different parameters. Current Research in Bioinformatics. 9, 35-44.

Ni, Q., Zhang, Z. L., \& Wang, L. (2011). Application of the differential transformation method to vibration analysis of pipes conveying fluid. Applied Mathematics and Computation, 217(16), 7028-7038.

Païdoussis, M. P. (1970). Dynamics of tubular cantilevers conveying fluid. Journal of Mechanical Engineering Science, 12(2), 85-103.

Païdoussis, M. P. (1981). Fluidelastic vibration of cylinder arrays in axial and cross flow: state of the art. Journal of Sound and Vibration, 76(3), 329-360.

Païdoussis, M. P. (1998). Fluid-structure interactions: slender structures and axial flow (Vol. 1). Academic press.

Païdoussis, M. P., \& Besancon, P. (1981). Dynamics of arrays of cylinders with internal and external axial flow. Journal of Sound and Vibration, 76(3), 361-379.

Païdoussis, M. P., \& Curling, L. R. (1985). An analytical model for vibration of clusters of flexible cylinders in turbulent axial flow. Journal of Sound and Vibration, 98(4), 493-517.

Païdoussis, M. P., \& Li, G. X. (1993). Pipes conveying fluid: A model dynamical problem. Journal of fluids and Structures, 7(2), 137-204.

Païdoussis, M. P., \& Moon, F. C. (1988). Nonlinear and chaotic fluidelastic vibrations of a flexible pipe conveying fluid. Journal of Fluids and Structures, 2(6), 567-591. 
Païdoussis, M. P., Semler, C., Wadham-Gagnon, M., \& Saaid, S. (2007). Dynamics of cantilevered pipes conveying fluid. Part 2: dynamics of the system with intermediate spring support. Journal of Fluids and Structures, 23(4), 569-587.

Rao, S. S. (2004). The Finite Element Method in Engineering. Miami.

Rao, S. S. (2011). Mechanical Vibrations.[S1].

Sadeghi, M. H., \& Karimi-Dona, M. H. (2011). Dynamic behavior of a fluid conveying pipe subjected to a moving sprung mass-an FEM-state space approach. International Journal of Pressure Vessels and Piping, 88(4), 123-131.
Shizhong, W., Yulan, L., \& Wenhu, H. (1998). Research on solid-liquid coupling dynamics of pipe conveying fluid. Applied mathematics and mechanics, 19(11), 1065-1071.

Zhai, H. B., Wu, Z. Y., Liu, Y. S., \& Yue, Z. F. (2011). Dynamic response of pipeline conveying fluid to random excitation. Nuclear Engineering and Design, 241(8), 2744-2749. 